\title{
Synthesis and Characterization of Polyaniline/Magnetite Nanocomposite
}

\author{
Rurik Farias-Mancilla1, José T. Elizalde-Galindo', Enrique Vigueras-Santiago², Claudia A. \\ Hernández-Escobar ${ }^{3}$, Alejandro Vega-Rios ${ }^{3}$, E. Armando Zaragoza-Contreras ${ }^{3}$ \\ ${ }^{1}$ Universidad Autónoma de Ciudad Juárez. \\ Av. del Charro 450 Norte. Cd. Juárez, Chihuahua, México \\ rurik.farias@uacj.mx; jose.elizalde@uacj.mx \\ 2Universidad Autónoma del Estado de México \\ Paseo Colón Esquina Paseo Tollocan s/n, CP 50000 Toluca, Estado de México, México \\ enriquevigueras@yahoo.com.mx \\ ${ }^{3}$ Centro de Investigación en Materiales Avanzados, S.C., \\ Miguel de Cervantes No. 120, Complejo Industrial Chihuahua, Chihuahua, Chih., México \\ claudia.hernandez@cimav.edu.mx; alejandro.vega@cimav.edu.mx; armando.zaragoza@cimav.edu.mx
}

\begin{abstract}
A conducting-electroactive polyaniline/magnetite $\left(\mathrm{PAni} / \mathrm{Fe}_{3} \mathrm{O}_{4}\right)$ nanocomposite was synthesized using anilinium dodecylbenzene sulfonate (S1) as a reactive surfactant. First, S1 allowed magnetite dispersion in the aqueous phase and second, $S 1$ performed as the monomer of polyaniline emeraldine base salt. Electron microscopy suggested core-shell morphology based on S1 amphiphilic character; that is, S1 adsorbed onto the magnetite nanoparticles surface and then was polymerized via an oxidative polymerization forming the shell. The PAni/Fe $\mathrm{F}_{3} \mathrm{O}_{4}$ composite exhibited improved thermal stability regarding pure PAni, which was related to the strong interaction between PAni and magnetite. Electrical conductivity, determined by the four-probe method, was in the order of $10^{-1}$ and $10^{-3} \mathrm{~S} \mathrm{~cm}^{-1}$, respectively, for the pure PAni and the composite. Concerning composite magnetic properties, the decrement in magnetization $\left(\sigma_{r}\right)$ and hysteresis $\left(H_{c}\right)$ was attributed to the increment in dipolar magnetic interaction due to the increased separation among magnetite nanoparticles because of the PAni shell.
\end{abstract}

Keywords: Conducting polymer, Nanocomposite, Magnetite, Polyaniline, Reactive surfactant.

(C) Copyright 2016 Authors - This is an Open Access article published under the Creative Commons Attribution License terms (http://creativecommons.org/licenses/by/3.0). Unrestricted use, distribution, and reproduction in any medium are permitted, provided the original work is properly cited.

\section{Introduction}

Magnetic polymer nanocomposites represent a class of functional materials, where magnetic nanoparticles are embedded in polymer matrices [1][3]. These nanocomposites hold great potential for applications in, for example, storage information, power distribution, microwave communication, permeability and microwave absorption, electromagnetic device application, shape-memory, and electromagnetic interference suppression [4]-[7]. Conducting polymers have received special attention because of their excellent electrical properties and tunable conductivities [8]. Particularly, polyaniline (PAni) has been subject of intense study during the past decades because of its excellent electrical and chemical properties [9]. PAni displays novel properties such as special doping mechanisms and high environmental stability [10]. Furthermore, metal oxides with the spinel structure constitute an important class of materials exhibiting a wide variety of electrical, magnetic, and optical properties [11]. Magnetite $\left(\mathrm{Fe}_{3} \mathrm{O}_{4}\right)$ is a common ferrite-possessing material with a cubic inverse spinel structure. Stable magnetite with high crystallinity and magnetic responses can be easily manufactured [12].

The study of PAni composites containing magnetite has been extensive; these materials are usually investigated due to their unique magnetic and electrical characteristics; for example, Xiao et al. [13] synthesized $\mathrm{PAni} /$ nano- $\mathrm{Fe}_{3} \mathrm{O}_{4}$ composites prepared in a 
$\mathrm{Fe}_{3} \mathrm{O}_{4}$ nanoparticle stabilized Pickering emulsion. They found that composite morphology and roomtemperature conductivity depended not only on the volume ratio of toluene to water, but also on $\mathrm{Fe}_{3} \mathrm{O}_{4}$ loading in the reaction system. Chung et al. [14] reported the fabrication of PAni hollow spheres using polystyrene particles as the template. Subsequently, they synthesized $\mathrm{PAni} / \mathrm{Fe}_{3} \mathrm{O}_{4}$ nanocomposites with $\mathrm{Fe}_{3} \mathrm{O}_{4}$ on the surface of the PAni hollow cluster structures by in-situ and ex-situ methods. The hollow morphology of the PAni particles, after removing polystyrene with acetone, was characterized by electron microscopy. The $\mathrm{Fe}_{3} \mathrm{O}_{4}$ nanoparticles synthesized with the ex-situ method were more widespread on the surface of PAni hollow spheres as compared with their counterparts synthesized with the in-situ method. De Araújo et al. produced polyaniline$\mathrm{Fe}_{3} \mathrm{O}_{4}$ nanocomposite using $\mathrm{Fe}_{3} \mathrm{O}_{4}$ nanoparticles as the oxidizing agent. Conductivity for the pure magnetite and the nanocomposites were, respectively, in the order of $10^{-6}$ and $10^{-5} \mathrm{~S} \mathrm{~cm}^{-1}$, confirming conductivity increment as a function of PAni loading. Furthermore, the magnetic measurements showed ferromagnetic behavior for the nanoparticles, with high-saturated magnetization ( $M S=74.30 \mathrm{emu}^{-1}$ ) and a coercive force of 93.40 Oe [15]. Jacobo et al. reported a process for the preparation of composite films consisting of $\mathrm{Fe}_{3} \mathrm{O}_{4}$ nanoparticles embedded in a PAni matrix. The films showed both reasonably high electrical conductivity and magnetic permeability. Application of an external magnetic field during composite synthesis stimulated creation of magnetic particle aggregates which, although kept conductivity at a relatively high level left to a small decrease of the conductivity value [16]. Aphesteguy et al. reported the preparation of a processible $\mathrm{Fe}_{3} \mathrm{O}_{4}$ /PAni nanocomposite, using dodecylbenzen sulfonic acid (DBSA) as a surfactant and dopant. The nanocomposite showed at $300 \mathrm{~K}$ no loop of hysteresis indicating the superparamagnetic nature. Whereas the electrical conductivity of the composites was higher than that of the pure PAni despite of the insulating character of the magnetite particles inserted [17]. Basavaiah et al. prepared magnetic polyaniline/magnetite nanocomposites by an in situ self-assembly method in the presence of DBSA as dopant and surfactant. The nanocomposite morphology was dependent on the molar ratio of DBSA to aniline [18]. Additionally, the nanocomposites showed superparamagnetism and high thermal stability. Ding et al. produced nanocomposites consisting of PAni nanorods surrounded by $\mathrm{Fe}_{3} \mathrm{O}_{4}$ nanoparticles. They used DBSA as the dopant and as surfactant in the reaction system. DBSA allowed the control of the morphology and size of PAni nanorods and magnetite particles. Magnetite particles were formed simultaneously during sedimentation, and the formed nanorods were also decorated by the particles [19]. Radhakrishnan et al. reported the synthesis and characterization of DBSA doped polyaniline (PAni) and its magnetite composites. The composites showed excellent dispersibility in water and organic solvents. The composites were evaluated as electrode materials for supercapacitor applications; they found that the single electrode of composite and the symmetrical capacitor based on it showed, respectively, enhanced capacitance of 228 and $180 \mathrm{~F} \mathrm{~g}^{-1}$ at $1 \mathrm{~mA} \mathrm{~cm}^{-1}$. Besides, the capacitance values increased with decreased magnetite loadings [20]. Khorshidi et al. prepared magnetic and conducting polyaniline $/ \mathrm{Fe}_{3} \mathrm{O}_{4}$ nanoparticles in aqueous solution by using the sodium salt of DBSA as the surfactant. Composites conductivity decreased as a function of $\mathrm{Fe}_{3} \mathrm{O}_{4}$ content, producing values of $2.7 * 10^{-5}$ and $3.4 * 10^{-6} \mathrm{~S} \mathrm{~cm}^{-1}$, respectively, for loadings of 1 and $5 \mathrm{~g} \mathrm{~L}^{-1}$ of magnetite. Composite magnetic properties showed superparamagnetic behavior, such as saturated magnetization $(M s=1.8$ emu g-1 ${ }^{-1}$, remnant magnetization $\left(M_{r}=0\right)$, and coercive force $(\mathrm{HC}=0)$ [21]. Recently, application of polyaniline $/ \mathrm{Fe}_{3} \mathrm{O}_{4}$ composites in liquefied petroleum gas sensing [22], heavy-metal ion absorption [23], or microwave absorption [24] demonstrate the scientific interest for these materials and stimulates the exploration of new strategies of synthesis and new applications for future technologies.

As noted in the literature, there are a variety of strategies reported to obtain polyaniline/magnetite composites; the use of dodecylbenzene sulfonate as the doping agent and to control composite morphology and to provide solvent dispersibility is one. Taking inspiration from this concept, herein we report on the use of anilinium dodecylbenzene sulfate (S1) as a reactive surfactant; that is, $\mathrm{S} 1$ performs as a surfactant and is the monomer of polyaniline concurrently, Figure 1. As a surfactant, $\mathrm{S} 1$ assists in the dispersion of the magnetite nanoparticles in the aqueous phase and helps to counteract nanoparticles tendency to reagglomeration. As a monomer, through an oxidative polymerization, S1 produces conducting polyaniline (emeraldine base salt). Consequently, by using S1 both magnetite dispersion and polyaniline shell synthesis is 
possible, producing a core-shell composite with magnetic, electro-conductive, and electro-active properties.

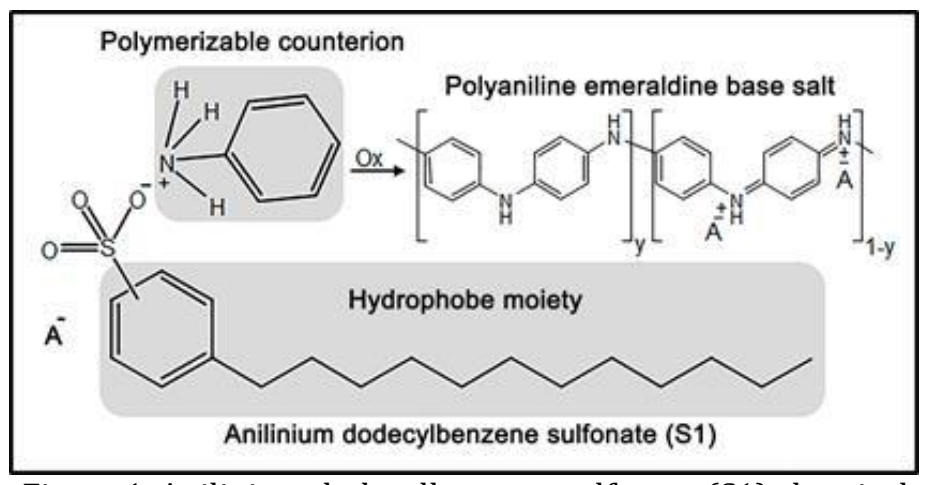

Figure 1. Anilinium dodecylbenzene sulfonate (S1) chemical structure. By an oxidative polymerization $\mathrm{S} 1$ is polymerized to polyaniline emeraldine base salt. The dodecylbenzene sulfonate group provides S1 with surfactant properties; additionally, after polymerization this group performs as the doping agent and improves dispersibility in the aqueous phase and organic solvents.

\section{Experimental Section}

\section{1. Synthesis of $\mathrm{Fe}_{3} \mathrm{O}_{4}$ Nanoparticles}

Magnetite $\left(\mathrm{Fe}_{3} \mathrm{O}_{4}\right)$ was synthesized following the method reported by Vergés et al. [12], this method used the $\mathrm{FeSO}_{4}$ salt precipitation in the presence of a base $(\mathrm{NaOH})$ and a mild oxidant $\left(\mathrm{KNO}_{3}\right)$. Optimal conditions for this synthesis were at concentrations of: a) ferrous solution containing $0.1 \mathrm{M} \mathrm{FeSO}_{4} \cdot 7 \mathrm{H}_{2} 0$ and $0.01 \mathrm{M} \mathrm{H}_{2} \mathrm{SO}_{4}$; b) oxidation solution containing $0.07 \mathrm{M} \mathrm{NaOH}$ and $0.1 \mathrm{M}$ $\mathrm{KNO}_{3}$. The two solutions were mixed by adding ferrous solution to the first solution at a constant rate of $60 \mathrm{~mL}$ $\min ^{-1}$, under stirring and inert atmosphere $\left(\mathrm{N}_{2}\right)$ reaching $\mathrm{pH}>11$ during the reaction; a green phase of iron salt was obtained in the solution. After, the solution was thermally aged at $90{ }^{\circ} \mathrm{C}$ during $24 \mathrm{~h}$ to obtain a magnetite stable phase. Then, the solution was cooled down at room temperature; the precipitate obtained was magnetically decanted, washed, and dried.

\section{2. Synthesis of Polyaniline $/ \mathrm{Fe}_{3} \mathrm{O}_{4}$ Composites}

Magnetite/polyaniline composites were synthesized as follows: First, an aqueous dispersion of magnetite, in the presence of $\mathrm{S} 1$, was prepared using a dismembrator (Model 505, Fisher Scientific) programmed to apply pulses at $100 \%$ amplitude every $2 \mathrm{~s}$ for $60 \mathrm{~min}$. Afterwards, an aqueous solution of ammonium persulfate (APS) at a molar ratio APS to S1 of 1.2:1.0 was added dropwise over a period of $30 \mathrm{~min}$. The oxidative polymerization was left at $-2{ }^{\circ} \mathrm{C}$ for $24 \mathrm{~h}$.

\section{3. Characterization}

Scanning electron microscopy in transmission mode (STEM) was performed in a field emission electron microscope (JSM-7401F; JEOL) at $30 \mathrm{KV}$. To prepare the samples, a drop of aqueous dispersion, of magnetite or magnetite/polyaniline composite, was dispersed by sonication for $5 \mathrm{~min}$ in $30 \mathrm{~mL}$ of distilled water. Subsequently, a drop of dispersion was placed and left dry on a holey-carbon-cooper grid. $X$ ray diffraction (XRD) pattern of the pure magnetite was obtained at room temperature using an X-ray diffractometer (Expert Pro, PANAlytical) with $\mathrm{Cu}-\alpha$ radiation. All peaks were identified with the magnetite cubic crystalline phase (PDF-3 01-075-0449). The composite was characterized using a thermogravimetric analyzer (TGA Q500, TA Instruments). Measurement was achieved using $10 \mathrm{mg}$ of sample and heated from laboratory temperature to $950{ }^{\circ} \mathrm{C}$, at a heating rate of $10{ }^{\circ} \mathrm{C} \mathrm{min}-1$ under air atmosphere. Composite conductivity was determined by the four-probe technique. Assays were achieved on probes of $10 \mathrm{~mm}$ in diameter $* 0.2 \mathrm{~mm}$ wide, prepared by compression at laboratory conditions. The PAni $/ \mathrm{Fe}_{3} \mathrm{O}_{4}$ composite was characterized by cyclic voltammetry (CV) using a potentiostate analyzer (model 1260 plus 1287, Solartron). Electrochemical measurements were performed in a standard threeelectrode cell at room temperature, using Pt square foil (area $=0.75 \mathrm{~cm}^{2}$ ) as the counter electrode, and $\mathrm{Ag} / \mathrm{AgCl} /$ saturated $\mathrm{KCl}$ as the reference electrode. The electrolyte was a sulfuric acid $\left(\mathrm{H}_{2} \mathrm{SO}_{4}\right)$ solution $0.1 \mathrm{M}$. The analysis was performed at a scan rate of $50 \mathrm{mV} \mathrm{s}^{-1}$ by sweeping the potential from -500 to $+1000 \mathrm{mV}$ against $\mathrm{Ag} / \mathrm{AgCl}$ reference electrode. Working electrode was made with carbon paste depositing $5 \mathrm{mg}$ of composite. Magnetic measurements were run at room temperature using a magnetometer (Versalab Crio Free VSM, Quantum Design) with maximum applied field $H_{\max }=20 \mathrm{kOe}$.

\section{Results and Discussion}

\section{1. Morphology}

Figure 2(a) portrays an image of electron microscopy of the pure magnetite nanoparticles. As observed, the sample consists of nanometric semispherical particles with wide polydispersity. 
Concerning the composites, Figure 2 (b and c), the presence of the polyaniline is observed as the grey cloud embedding the magnetite nanoparticles. In these, the intimate interaction between both materials is evident. This result is explained in terms of the surface activity of S1; that is, as S1 is a surfactant it is adsorbed onto the magnetite nanoparticles creating an interphase that reduces nanoparticle reagglomeration. When the oxidizing agent is added, S1 polymerization is achieved forming a layer of polyaniline on the nanoparticle surface. Consequently, S1 character both as a surfactant and monomer of polyaniline was evidenced, and the core-shell microstructure of the composite was assumed. Figure $2 \mathrm{~d}$ shows magnetite nanoparticles statistical data. Average particle size $\left(D_{A V}\right)$, considering nanoparticles as spheres, is $17.7 \mathrm{~nm}$. According to the analysis and considering a standard deviation $(\sigma)$ of 7.5 $\mathrm{nm}, 72 \%$ of the nanoparticles are close to the most probable particle size, in this case $12.5 \mathrm{~nm}$.
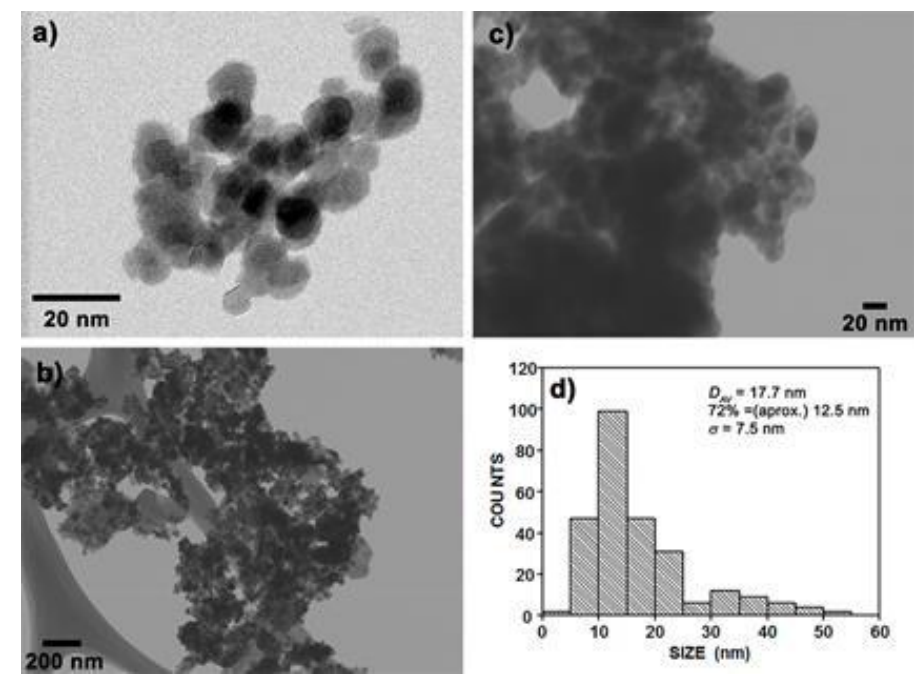

Figure 2. STEM micrographs of a) pure magnetite, b) $\mathrm{PAni} / \mathrm{Fe}_{3} \mathrm{O}_{4}$ composite at low magnifications, c) PAni/ $/ \mathrm{Fe}_{3} \mathrm{O}_{4}$ composite at high magnification, and d) statistical analysis of magnetite particle size distribution.

\section{2. Magnetite Crystalline Structure}

Figure 3 shows the XRD pattern of the pure magnetite. The diffraction peaks at $2 \theta=30.2,35.6,43.3$, $53.5,57.2$, and 63.03 correspond to (220), (311), (400), (422), (511), and (440) crystallographic planes of the spinel phase of Fe304, respectively; this pattern is in accordance with literature reported [25]. As noted, no peaks of any secondary phase were observed. Average crystallite size was calculated using Scherrer Equation (1):

$$
<D>=\kappa \lambda / \beta \cos \theta
$$

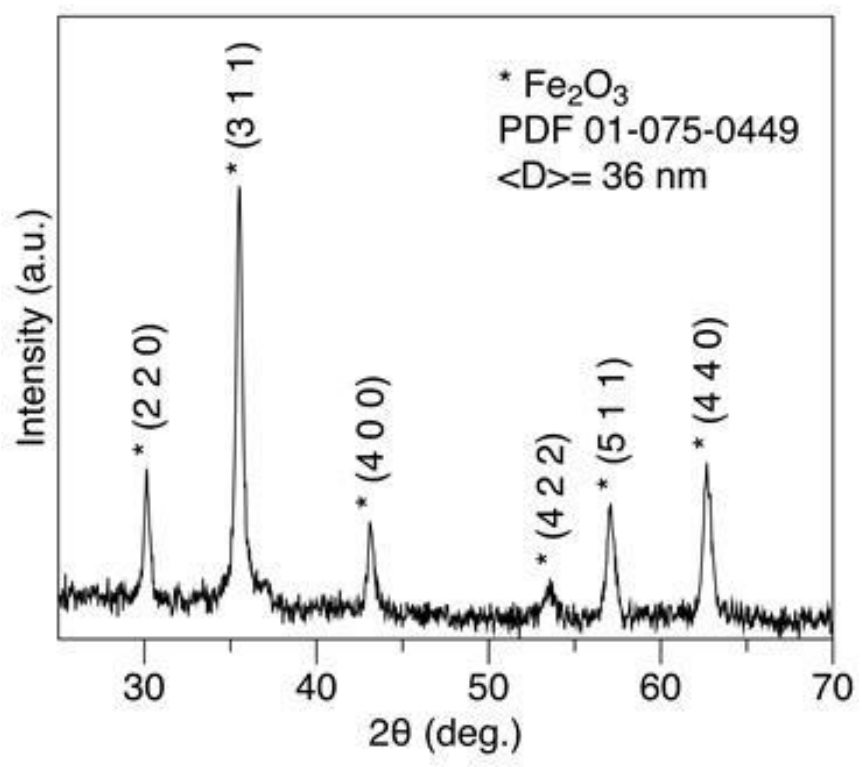

Figure 3. XRD pattern of the pure magnetite nanoparticles.

where $\lambda$ is the X-ray wavelength $(\lambda=0.154 \mathrm{~nm})$, $<D>$ is the average crystallite size, $\kappa$ is the dimensionless shape factor, $\beta$ is the full-width at half the maximum (FWHM), and $\theta$ is the Bragg angle in degree. The shape factor $\kappa$ is normally 0.89 . Using the FWHM of the most intense peak $(2 \theta=35.6)$ giving $\langle D\rangle=36+/-1 \mathrm{~nm}$. UNITCELL software was used to calculate the lattice parameters. Values of $a=8.370(1) \AA$ resulted, which indicates that lattice parameter is not affected by synthesis process [26].

\section{3. Thermal Stability}

Figure 4 shows thermogravimetric analysis traces of the pure polyaniline and the $\mathrm{PAni} / \mathrm{Fe}_{3} \mathrm{O}_{4}$ composite. Concerning polyaniline, the initial weight loss above $150{ }^{\circ} \mathrm{C}$ is ascribed to water evaporation and to degradation of low molecular weight species (for instance, unattached dopant or PAni oligomers). The second mass loss close to $250{ }^{\circ} \mathrm{C}$ was associated with the doping agent degradation. Subsequently, the transition at $350{ }^{\circ} \mathrm{C}$ was attributed to polyaniline backbone decomposition [27], [28]. Concerning the composite, the first transition is equivalent to that observed in the pure PAni; however, the second and third transitions appeared, respectively, at $325{ }^{\circ} \mathrm{C}$ and $470{ }^{\circ} \mathrm{C}$; that is, $75^{\circ} \mathrm{C}$ and $100{ }^{\circ} \mathrm{C}$ higher than in the pure PAni. Such enhanced thermal stability was related to the strong interfacial interaction between PAni and 
magnetite, which restricts thermal motion of PAni chains [18], [29], [30]. Finally, it is worth mentioning, that the analysis indicated a composite composition close to $50 \mathrm{wt} \%$ of PAni and magnetite. This value indicates a high conversion of S1 to PAni, as in the initial formulation a weight ratio of $1: 1$ (wt/wt) of $\mathrm{S} 1$ to magnetite was used.

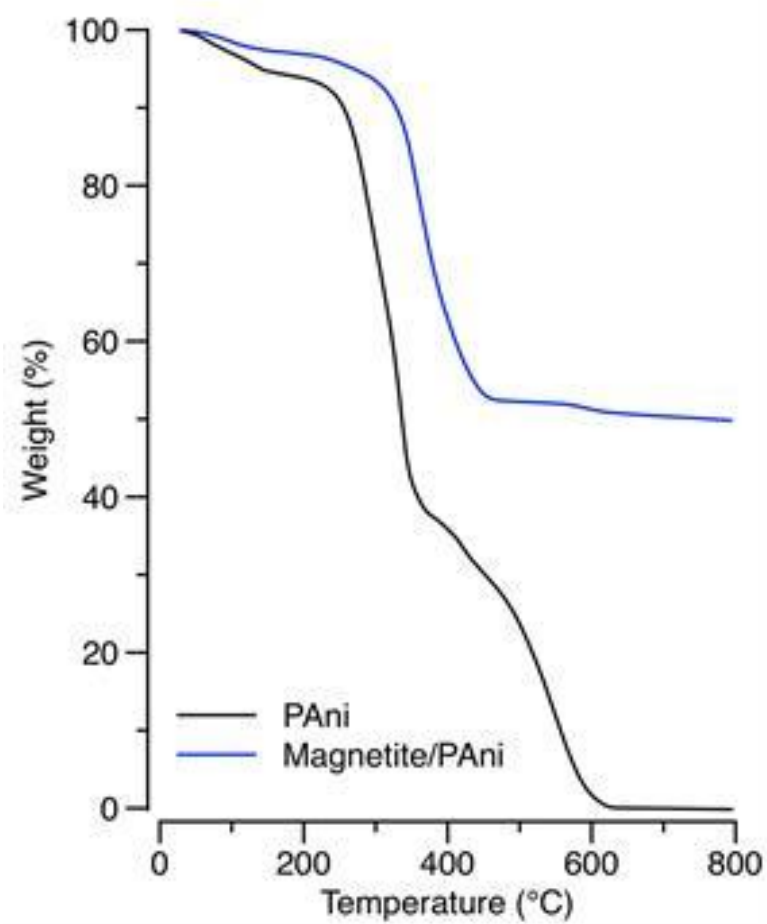

Figure 4. Thermogravimetric traces of the pure polyaniline and polyaniline/magnetite composite. The analyses were performed at a heating rate of $10{ }^{\circ} \mathrm{C} \mathrm{min}-1$ under air atmosphere.

\section{4. Electrical Properties}

Electro-conductivity of the pure PAni and the $\mathrm{PAni} / \mathrm{Fe}_{3} \mathrm{O}_{4}$ composite was, respectively, $3.08 \times 10^{-1}$ and $3.51 \times 10^{-3} \mathrm{~S} \mathrm{~cm}^{-1}$. Concerning the pure magnetite, we had no result as an adequate tablet to achieve this measurement was not obtained. Considering literature, the usual behavior is the reduction of electroconductivity at high magnetite loadings, such behavior has been related to the charge transport mechanism [31], [32]. Similar behavior has been reported for other magnetic materials [33], [34].

Figure 5 shows voltammograms of the pure polyaniline, magnetite, and $\mathrm{PAni} / \mathrm{Fe}_{3} \mathrm{O}_{4}$ composite. As expected, magnetite showed no electrochemical response. Concerning the pure PAni and the composite, during cycling the positive range was swept from the half-doped state, called emeraldine, to fully the doped state, called pernigraniline. Furthermore, the negative range was swept from half-doped state to fully dedoped state, called leucoemeraldine. Both leucoemaraldine and pernigraniline states are non-conducting in nature, and offer high resistance. At high cell voltage, PAni does not have sufficient ion exchange sites to get doped; hence, a decrease in the current above $0.6 \mathrm{~V}$ occurred. According to literature, polyaniline voltammetric responses to acidic media has two coupling redox potentials for the range of $-0.2 \mathrm{~V}<\mathrm{V}<1 \mathrm{~V}$ [35]. In the potential range from -0.2 to $1 \mathrm{~V}$, the compounds show a redox couple manifested as two voltammetric peaks. These peaks are not symmetric regarding the shape or position on the potentials axis. The cathodic peak is always wider and appears at inferior potential values.

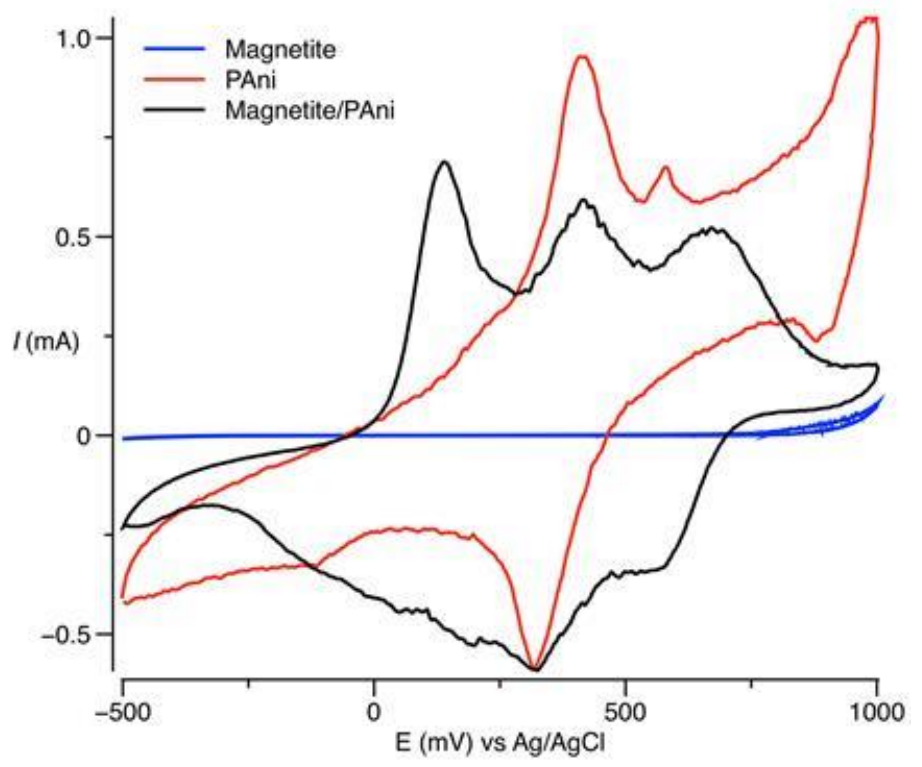

Figure 5. Voltammograms of the pure polyaniline, magnetite, and $\mathrm{PAni} / \mathrm{Fe}_{3} \mathrm{O}_{4}$ composite. The electrolyte was a sulfuric acid $\left(\mathrm{H}_{2} \mathrm{SO}_{4}\right)$ solution $0.1 \mathrm{M}$. The analysis was performed at a scan rate of $50 \mathrm{mV} \mathrm{s}^{-1}$ by sweeping the potential between -500 and $+1000 \mathrm{mV}$ against $\mathrm{Ag} / \mathrm{AgCl}$ reference electrode.

\section{5. Magnetic Properties}

Figure 6 shows the hysteresis loop measured at room temperature with a $H_{\max }$ of $20 \mathrm{kOe}$ for $\mathrm{Fe}_{3} \mathrm{O}_{4}$ and PAni/ $\mathrm{Fe}_{3} \mathrm{O}_{4}$ composite. The saturation magnetization value $\left(\sigma_{s}\right)$ for $\mathrm{Fe}_{3} \mathrm{O}_{4}$ and $\mathrm{PAni} / \mathrm{Fe}_{3} \mathrm{O}_{4}$ composite were, respectively, 58 and $50 \mathrm{emu} \mathrm{g}^{-1}$. These values are low contrasting with the reported theoretical saturation magnetization in magnetite (92 $\mathrm{emu} \mathrm{g}^{-1}$ ), and to the value of commercial magnetite fine powder (84.5 emu g1) [36]. For the $\mathrm{Fe}_{3} \mathrm{O}_{4}$ nanoparticles, the lowering on the 
saturation magnetization could be attributable to morphology and superficial effects such as oxidation differences. Another reason could be a lack of symmetry at the surface, which yields to broken ligands. This caused a deficiency in super-exchange interaction between close-to-surface iron atoms. In addition, if a superficial oxygen layer is formed, the linked electrons cannot participate in super-exchange anymore, resulting in a decrease of net magnetization [37].

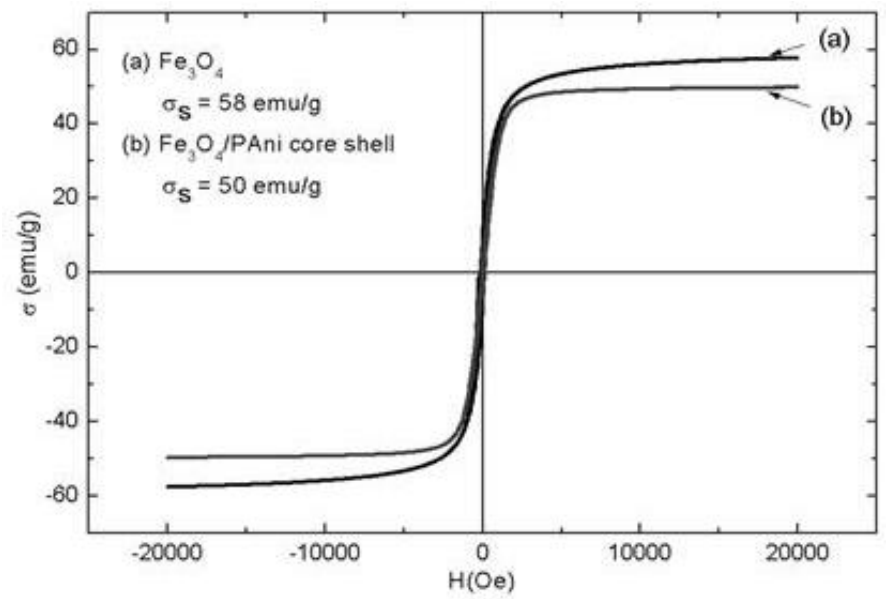

Figure 6. Hysteresis loops of the pure magnetite and $\mathrm{PAni} / \mathrm{Fe}_{3} \mathrm{O}_{4}$ composite. Measurements were run at room temperature with a $H_{\max }$ of $20 \mathrm{kOe}$.

Meanwhile, for the PAni/ $\mathrm{Fe}_{3} \mathrm{O}_{4}$ composite, the reduction in $\sigma_{s}$ was attributed to the reduction in magnetic mass, as PAni is not contributing to magnetization values. Since the critical diameter for superparamagnetic behavior in $\mathrm{Fe}_{3} \mathrm{O}_{4}$ is $20 \mathrm{~nm}$, and because the average crystallite size reached for our $\mathrm{Fe}_{3} \mathrm{O}_{4}$ nanoparticles is $36 \mathrm{~nm}$, a ferrimagnetic behavior in both samples was expected [11]. Consequently, the remnant magnetization between 8 and $4 \mathrm{emu} \mathrm{g}^{-1}$ and coercivity between 100 and 60 0e were exposed. The lower values of $\sigma_{r}$ and $H_{c}$ observed in PAni/ $/ \mathrm{Fe}_{3} \mathrm{O}_{4}$ composite were attributed to the increment in dipolar magnetic interaction due to PAni shell formed onto the $\mathrm{Fe}_{3} \mathrm{O}_{4}$ nanoparticles surface.

\section{Conclusion}

S1 was successfully used for the synthesis of $\mathrm{PAni} / \mathrm{Fe}_{3} \mathrm{O}_{4}$ composites. First, $\mathrm{S} 1$ facilitated the dispersion of the $\mathrm{Fe}_{3} \mathrm{O}_{4}$ nanoparticles in the reaction medium and then, through an oxidative polymerization, produced the shell providing the composite with conductive-electroactive properties. The $\mathrm{PAni} / \mathrm{Fe}_{3} \mathrm{O}_{4}$ composite exhibited enhanced thermal stability compared to the pure PAni, which evidence the strong interfacial interaction between both components. Concerning electrical conductivity, values of $10^{-1}$ and $10^{-}$ ${ }^{3} \mathrm{~S} \mathrm{~cm}^{-1}$ for the pure PAni and the PAni/ $/ \mathrm{Fe}_{3} \mathrm{O}_{4}$ composite, respectively, obeyed the typical behavior reported for similar systems. The $\mathrm{Fe}_{3} \mathrm{O}_{4}$ nanoparticles exposed a ferrimagnetic behavior, with a saturation magnetization of $58 \mathrm{emu}^{-1}$. After formation of the PAni shell, the magnetic properties shifted to lower values due to magnetic mass reduction and to the enhanced magnetic dipolar interactions because of the separation between $\mathrm{Fe}_{3} \mathrm{O}_{4}$ nanoparticles.

\section{Acknowledgement}

We gratefully acknowledge financial support by PROMEP-SEP, Program: Redes Temáticas de Colaboración Académica, for "Red de Compuestos Poliméricos, Propiedades y Aplicaciones". We also wish to thank to Laboratorio Nacional de Nanotechnología (CIMAV), and to Wilber Antunez and Carlos Ornelas for their helpful collaboration during this research.

\section{References}

[1] X. Liu, Y. Guan, Z. Ma, and H. Liu, "Surface modification and characterization of magnetic polymer nanospheres prepared by miniemulsion polymerization.," Langmuir, vol. 20, no. 23, pp. 10278-82, 2004.

[2] I. Csetneki, M. K. Faix, A. Szilágyi, A. L. Kovács, Z. Németh, and M. Zrinyi, "Preparation of magnetic polystyrene latex via the miniemulsion polymerization technique," J. Polym. Sci. Part A Polym. Chem., vol. 42, no. 19, pp. 4802-4808, 2004.

[3] G. Qiu, Q. Wang, C. Wang, W. Lau, and Y. Guo, "Polystyrene/Fe304 magnetic emulsion and nanocomposite prepared by ultrasonically initiated miniemulsion polymerization.," Ultrason. Sonochem., vol. 14, pp. 55-61, 2007.

[4] R. Mohr, K. Kratz, T. Weigel, M. Lucka-Gabor, M. Moneke, and A. Lendlein, "Initiation of shapememory effect by inductive heating of magnetic nanoparticles," PNAS, vol. 103, pp. 3540-3545, 2006.

[5] L. A. Dobrzański, M. Drak, and B. Ziębowicz, "New possibilities of composite materials applicationMaterials of specific magnetic properties," J. Mater. Process. Technol., vol. 191, pp. 352-355, 2007. 
[6] I. Kong, S. H. Ahmad, M. H. Abdullah, D. Hui, A. N. Yusoff, and D. Puryanti, "Magnetic and microwave absorbing properties of magnetite-thermoplastic natural rubber nanocomposites," J. Magn. Magn. Mater., vol. 322, pp. 3401-3409, 2010.

[7] B. Belaabed, J. L. Wojkiewicz, S. Lamouri, N. El Kamchi, and T. Lasri, "Synthesis and characterization of hybrid conducting composites based on polyaniline/magnetite fillers with improved microwave absorption properties," J. Alloys Compd., vol. 527, pp. 137-144, 2012.

[8] J. Pyun, "Nanocomposite Materials from Functional Polymers and Magnetic Colloids," Polym. Rev., vol. 47, pp. 231-263, 2007.

[9] E. T. Kang, K. G. Neoh, and K. L. Tan, "Polyaniline: A polymer with many intrinsic redox states," Prog. Polym. Sci., vol. 23, pp. 277-324, 1998.

[10] Y. S. Negi and P. V. Adhyapak, "Development in Polyaniline Conducting Polymers," J. Macromol. Sci. Part C Polym. Rev., vol. 42, pp. 35-53, 2002.

[11] A.-H. Lu, E. L. Salabas, and F. Schüth, "Magnetic nanoparticles: synthesis, protection, functionalization, and application.," Angew. Chemie Int. Ed., vol. 46, pp. 1222-1244, 2007.

[12] M. A. Vergés, R. Costo, A. G. Roca, J. F. Marco, G. F. Goya, C. J. Serna, and M. P. Morales, "Uniform and water stable magnetite nanoparticles with diameters around the monodomain-multidomain limit," J. Phys. D. Appl. Phys., vol. 41, p. 134003, 2008.

[13] Q. Xiao, X. Tan, L. Ji, and J. Xue, "Preparation and characterization of polyaniline/nano-Fe304 composites via a novel Pickering emulsion route," Synth. Met., vol. 157, pp. 784-791, 2007.

[14] Y. Chung, S.-R. Yun, C.-W. Lee, N.-J. Jo, C.-H. Yo, and K.-S. Ryu, "Inorganic/Organic Nanocomposites of Polyaniline and Fe 304 with Hollow Cluster Structures using Polystyrene Template," Bull. Korean Chem. Soc., vol. 31, no. 7, pp. 2065-2068, 2010.

[15] A. C. V. de Araújo, R. J. de Oliveira, S. Alves Jr, A. R. Rodrigues, F. L. A. Machado, F. A. O. Cabral, and W. M. de Azevedo, "Synthesis, characterization and magnetic properties of polyaniline-magnetite nanocomposites," Synth. Met., vol. 160, pp. 685690, 2010.

[16] S. E. Jacobo, J. C. Aphesteguy, R. Lopez Anton, N. N. Schegoleva, and G. V. Kurlyandskaya, "Influence of the preparation procedure on the properties of polyaniline based magnetic composites," Eur. Polym. J., vol. 43, no. 4, pp. 1333-1346, 2007.

[17] J. C. Aphesteguy and S. E. Jacobo, "Synthesis of a soluble polyaniline - ferrite composite : magnetic and electric properties," J. Mater. Sci., vol. 42, pp. 7062-7068, 2007.

[18] K. Basavaiah, Y. P. Kumar, and A. V. P. Rao, "A facile one-pot synthesis of polyaniline/magnetite nanocomposites by micelles-assisted method," Appl. Nanosci., vol. 3, pp. 409-415, 2013.

[19] X. Ding, D. Han, Z. Wang, X. Xu, L. Niu, and Q. Zhang, "Micelle-assisted synthesis of polyaniline/magnetite nanorods by in situ selfassembly process.," J. Colloid Interface Sci., vol. 320, pp. 341-345, 2008.

[20] S. Radhakrishnan, C. R. K. Rao, and M. Vijayan, "Performance of Conducting Polyaniline-DBSA and Polyaniline-DBSA / Fe304 Composites as Electrode Materials for Aqueous Redox Supercapacitors," J. Appl. Polym. Sci., vol. 122, pp. 1510-1518, 2011.

[21] H. R. Khorshidi, H. Eisazadeh, and A. R. Khesali, "Preparation and characterization of polyaniline containing $\mathrm{Fe} 304$ nanoparticles using sodium dodecylbenzenesulfonate as a surfactant," High Perform. Polym., vol. 23, pp. 125-131, 2011.

[22] T. Sen, N. G. Shimpi, S. Mishra, and R. Sharma, "Polyaniline $/ \gamma$-Fe203 nanocomposite for room temperature LPG sensing," Sensors Actuators B, vol. 190, pp. 120-126, 2014.

[23] M. Rezvani, A. A. Asgharinezhad, $H$. Ebrahimzadeh, and N. Shekari, "A polyanilinemagnetite nanocomposite as an anion exchange sorbent for solid-phase extraction of chromium(VI) ions," Microchim. Acta, vol. 181, pp. 1887-1895, 2014.

[24] F. Xu, L. Ma, Q. Huo, M. Gan, and J. Tang, "Microwave absorbing properties and structural design of microwave absorbers based on polyaniline and polyaniline/magnetite nanocomposite," J. Magn. Magn. Mater., vol. 374, pp. 311-316, 2015.

[25] H. Gu, Y. Huang, X. Zhang, Q. Wang, J. Zhu, L. Shao, N. Haldolaarachchige, D. P. Young, S. Wei, and Z. Guo, "Magnetoresistive polyaniline-magnetite nanocomposites with negative dielectrical properties," Polymer, vol. 53, pp. 801-809, 2012.

[26] T. J. B. Holland and S. A. . Redfern, "Unit cell refinement from powder diffraction data: the use 
of regression diagnostics," Mineral. Mag., vol. 61, pp. 65-77, 1997.

[27] M. C. Arenas, E. Andablo, and V. M. Castaño, "Synthesis of Conducting Polyaniline Nanofibers from Single and Binary Dopant Agents," J. Nanosci. Nanotechnol., vol. 10, pp. 549-554, 2010.

[28] T. Hino, T. Namiki, and N. Kuramoto, "Synthesis and characterization of novel conducting composites of polyaniline prepared in the presence of sodium dodecylsulfonate and several water soluble polymers," Synth. Met., vol. 156, pp. 1327-1332, 2006.

[29] G. D. Prasanna, H. S. Jayanna, A. R. Lamani, and S. Dash, "Polyaniline/CoFe204 nanocomposites: A novel synthesis, characterization and magnetic properties," Synth. Met., vol. 161, pp. 2306-2311, 2011.

[30] L. Li, J. Jiang, and F. Xu, "Synthesis and ferrimagnetic properties of novel Sm-substituted LiNi ferrite-polyaniline nanocomposite," Mater. Lett., vol. 61, pp. 1091-1096, 2007.

[31] Z. Zhang and M. Wan, "Nanostructures of polyaniline composites containing nano-magnet," Synth. Met., vol. 132, pp. 205-212, 2003.

[32] S. Khasim, S. C. Raghavendra, M. Revanasiddappa, K. C. Sajjan, M. Lakshmi, and M. Faisal, "Synthesis, characterization and magnetic properties of polyaniline $/ \gamma$-Fe203 composites," Bull. Mater. Sci., vol. 34, pp. 1557-1561, 2011.

[33] J. Jiang, L. Ai, and L.-C. Li, "Synthesis and magnetic performance of polyaniline/Mn-Zn ferrite nanocomposites with intrinsic conductivity," J. Mater. Sci., vol. 44, pp. 1024-1028, 2009.

[34] W. Xue, H. Qiu, K. Fang, J. Li, J. Zhao, and M. Li, "Electrical and magnetic properties of the composite pellets containing DBSA-doped polyaniline and Fe nanoparticles," Synth. Met., vol. 156, pp. 833-837, 2006.

[35] H. Gómez, M. K. Ram, F. Alvi, P. Villalba, E. (Lee) Stefanakos, and A. Kumar, "Graphene-conducting polymer nanocomposite as novel electrode for supercapacitors," J. Power Sources, vol. 196, pp. 4102-4108, 2011.

[36] D. Thapa, V. R. Palkar, M. B. Kurup, and S. K. Malik, "Properties of magnetite nanoparticles synthesized through a novel chemical route," Mater. Lett., vol. 58, pp. 2692-2694, 2004.

[37] R. H. Kodama, A. E. Berkowitz, E. J. McNiff, and S. Foner, "Surface spin disorder in ferrite nanoparticles (invited)," J. Appl. Phys., vol. 81, p. 5552, 1997. 